\title{
Correction to: Optimisation on pretreatment of kapok seed (Ceiba pentandra) oil via esterification reaction in an ultrasonic cavitation reactor
}

\author{
Lai Fatt Chuah ${ }^{1,2}$. Awais Bokhari ${ }^{1,3}$. Suzana Yusup ${ }^{1}$. Jiří Jaromír Klemeš ${ }^{4}$ Majid Majeed Akbar ${ }^{5}$. \\ Sugesvarran Saminathan ${ }^{1}$
}

Published online: 16 September 2021

(c) Springer-Verlag GmbH Germany, part of Springer Nature 2021

Correction to: Biomass Conv. Bioref. (2017) 7:91-99

https://doi.org/10.1007/s13399-016-0207-9

In this article, reference 9 was incorrect.

The original article has been corrected.

Publisher's note Springer Nature remains neutral with regard to jurisdictional claims in published maps and institutional affiliations.

The original article can be found online at https://doi.org/10.1007/ s13399-016-0207-9.

Lai Fatt Chuah

1.f.chuah@outlook.com

1 Biomass Processing Laboratory, Centre of Biofuel and Biochemical Research (CBBR), Chemical Engineering Department, Universiti Teknologi PETRONAS, Bandar Seri Iskandar, 32610 Seri Iskandar, Perak, Malaysia

2 Marine Department Malaysia Northern Region, Gelugor, 11700 Penang, Malaysia

3 Chemical Engineering Department, COMSATS Institute of Information Technology, Lahore 54000, Pakistan

4 Faculty of Information Technology and Bionics, Pázmány Péter Catholic University, Práter u. 50/a, 1083 Budapest, Hungary

5 Institute of Chemical Engineering and Technology, University of the Punjab, Lahore, Pakistan 